\title{
Harvey Williams Cushing - великий хирург, \\ исследователь, эндокринолог, писатель, художник
}

\section{С.И. Рыбаков}

ГУ «Институт эндокринологии и обмена веществ им. В.П. Комиссаренко НАМН Украины»

В литературе имеется немалое количество сообщений о выдающихся личностях, которые посвятили свою жизнь науке и хирургии и добились всемирно признанных успехов на этом поприще. Достаточно назвать имена Н.И. Пирогова из России, Т. Billroth из Австрии, Т. Kocher из Швейцарии и еще многих, чьи имена навечно вписаны в историю медицины. В этом ряду достойное место принадлежит американскому хирургу Harvey Williams Cushing (Харвей Виллиамс Кушинг), основоположнику нового направления клинической хирургии - нейрохирургии, хирургу-виртуозу, выдающемуся эндокринологу, исследователю, писателю, художнику.

Во всех областях своей многообразной деятельности он оставил выдающиеся образцы, сохранившие непреходящее значение до нашего времени. Автор настоящего сообщения имел возможность дважды обращаться к имени этого человека, оставившего неизгладимый след в истории американской и мировой хирургии [1,2]. Упоминаемые работы освещали некоторые стороны его многогранной

* Адреса для листування (Correspondence): ДУ «Інститут ендокринології та обміну речовин ім. В.П. Комісаренка НАМН України», вул. Вишгородська, 69, м. Київ, 04114, Україна. E-mail: dr.rybakov@comcast.net.

(с) С.И. Рыбаков деятельности, в частности, историю описанного им синдрома, носящего его имя - Cushing's syndrome. Однако, этим не ограничивалась его многогранная активность и Н. Cushing

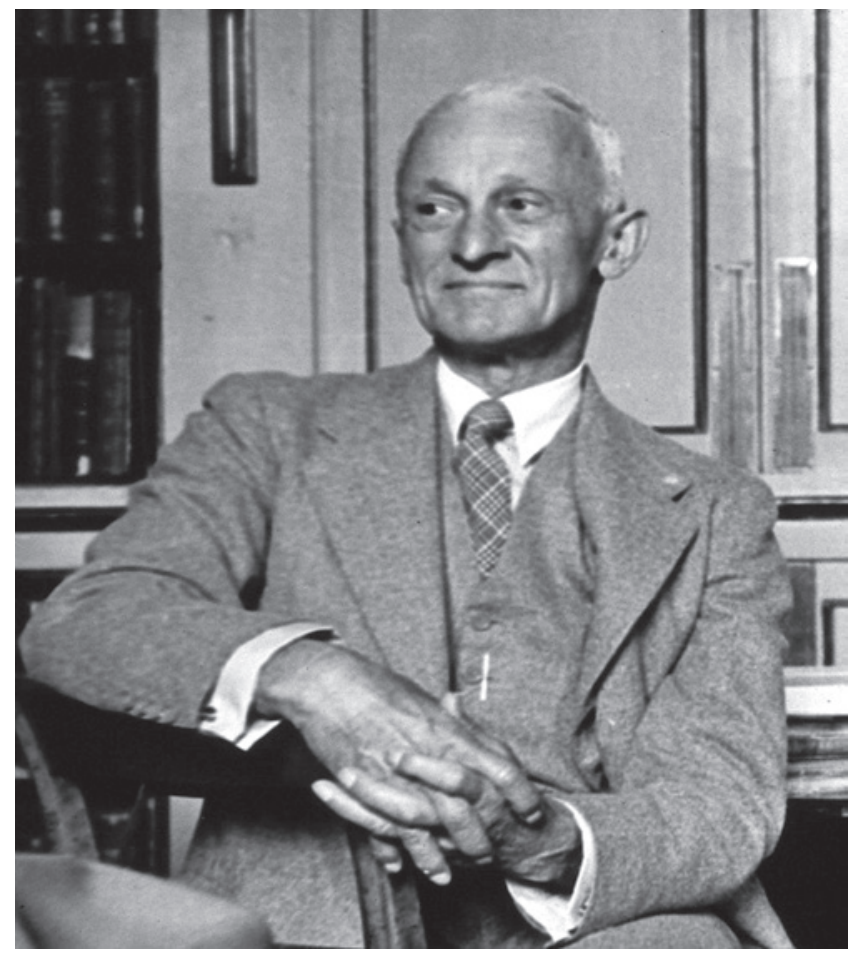

Фото 1. Харвей Виллиамс Кушинг

Photo 1. Harvey Williams Cushing 
Лекції

заслуживает, чтобы основные этапы его жизни и деятельности, хотя бы частично, стали достоянием Читателей.

H. Cushing [3, 4] появился на свет 8 апреля 1869 г. в г. Кливленде (штат Огайо, США) в семье Henry C. и Bettcy M. Cushing. Он был шестым сыном и десятым ребенком, из которых лишь семеро достигли совершенолетия. Указанные выше ссылки представляют две наиболее полные, академические биографии H. Cushing, которые детально освещают его жизненный и творческий путь. Отдельные статьи о нем, количество которых исчисляется сотнями, как правило, касаются деталей его биографии и деятельности и также представляют несомненный интерес.

Немногие могут похвалиться родословной, в частности медицинской, которая выпала на долю новорожденного. Его предок, сельский священник Mattew Cushing эмигрировал в Америку из Англии в 1638 г. Прадед David Cushing (1768-1814) был сельским врачом, дед Erastus Cushing (1802-1893) - врачом общей практики. Его отец занимался общей практикой и совмещал ее с преподавательской работой профессора на кафедрах акушерства и гинекологии и медицинской юриспруденции в Cleveland College of Medicine. Мать принадлежала к уважаемому старинному роду пионеров со Среднего Запада. Отец семейства был сдержанным, сухим и несколько суровым человеком. Заботы о воспитании детей он передал матери, но сам неукоснительно следил за их учебой и поведением. Один из братьев H. Cushing стал юристом, один - геологом и двое - врачами.

Детство и юность H. Cushing прошли в обеспеченной семье, но без особых излишеств. Учебу он начал в частной 2-летней школе, затем обучался 6 лет в Sterling Street Grammar School и Central High School of Clivlend. Параллельно занимался в Clivlend Mechanical Training School, заведении, которое сейчас можно было бы назвать «Ремесленное училище». Здесь ученики получали навыки работы с деревом, металлом, обучались черчению, основам механики. После окончания школы он поступил в престижный Yale University, где обучался в 1887-1891 гг. и по окончании которого с отличием получил степень бакалавра гуманитарных наук. В эти годы Н. Cushing вел обычную студенческую жизнь: помимо учебы, увлекался музыкой, баскетболом, греблей, проводил время в студенческих клубах и компаниях, к чему неодобрительно относился его отец, как видно из их переписки, считая, что подобная активность мешает получению полноценного образования.

В 1891 г. Н. Cushing по примеру своего старшего брата Edvard (Ned) поступает в знаменитую Harward Medical School в Бостоне. В то время обучение в школе было трехлетнее, а четвертый курс был факультативным. В период летних каникул и на четвертом году обучения он подрабатывал экстерном в Boston's Children Hospital и Massachusetts General Hospital.

Уже в эти годы H. Cushing отличался высокой активностью и жаждой знаний. К этому времени относятся его первые шаги и успехи в медицине, в частности в анестезиологии. В то время общее обезболивание являлось достаточно опасной процедурой и ему уделялось недостаточно внимания. Наркоз нередко давали студенты и медицинские сестры, следствием чего были частые осложнения и летальные исходы из-за недостатка внимания к состоянию больного.

После смерти одного больного, наркоз которому давал H. Cushing, он и его приятель, тоже студент A. Codman, в 1894 г. предложили для слежения за состоянием больного во время операции и наркоза специальную карту (Aether chart), в которой фиксировались частота пульса и количество дыханий, единственные в то время показатели, по которым оценивалось состояние больного по ходу вмешательства. После операции учитывали такой признак, как отсутствие или наличие посленаркозной рвоты. В последующем добавлялись другие показатели (температура, цвет кожи, артериальное давление) и комментарии о состоянии больного. В результате появилась возможность осуществлять мониторинг состояния больного и предупреждать или лечить различные осложнения.

В последующие годы H. Cushing неоднократно возвращался к вопросам обезболивания: изучал механизмы интраоперационной аспирации желудочного содержимого во время наркоза, предложил использовать стетоскоп для прекардиального мониторинга сердечного 
и дыхательнлго ритмов на протяжении операции, предложил специальные термины (регионарная анестезия и комбинированная общая анестезия) и первый ввел должность сестрыанестезистки [5-7].

В 1894 г., за год до окончания школы, H. Cushing совершил поездку в Европу, где посетил лаборатории таких выдающихся английских ученых как J. Hutshinson, T. Barlow и получил основопологающие представления о физиологических и патофизиологических процессах при хирургических заболеваниях. В последний год учебы он увлекся клиническим применением рентгеновских лучей, сам выполнял рентгенографию, обрабатывал пленки и представил одну из первых работ с описанием двух больных с пулевыми ранениями в голову. H. Cushing всячески пропагандировал этот метод исследований и предрекал ему большое будущее $[3,8]$. Интересно, что в 1988 г. в США была выпущена марка и открытка с портретом H. Cushing в память о его первом опыте применения рентгеновских лучей в неврологии.

Обучение в Harvard Medical School завершилось в 1896 г. Все эти годы Н. Cushing интенсивно занимался практической хирургией, диагностикой и параллельно осваивал основы научной исследовательской работы. Его поведение отличалось повышенным интересом, тщательным и внимательным отношением к больным, требовательностью к себе. Уже тогда проявилась его преданность медицине и верность профессиональному долгу. Так, в июне 1896 г. он даже не посетил выпускную церемонию в связи с окончанием Школы в связи с тем, что не мог оставить тяжелого больного [4].

Следующей ступенью в медицинской хирургической подготовке Н. Cushing, которая началась в 1896 г, явилась резидентура в недавно открывшемся John Hopkins Hospstal в Балтиморе под руководством выдающегося американского хирурга конца XIX и начала XX века W.S. Halsted (1852-1922) [3, 9]. Поначалу его впечатления от города и больницы были не очень оптимистические. Со свойственным молодости максимализмом H. Cushing осуждал организацию работы в госпитале, невысокий уровень асептики и даже низкую активность руководителя клиники, который в первый месяц выполнил лишь одну операцию.

Однако, в последующем Н. Cushing сменил свое мнение и отмечал, что он много почерпнул, работая с W. Halsted. Последний считался патриархом американской хирургии второй половины XIX и начала XX века. W. Halsted был широко известен своей хирургической деятельностью как общий хирург (операции при панкреатите, раке молочной железы, желудка, желчекаменной болезни, грыже и др.). Им была осуществлена реорганизация системы подготовки хирургов в виде резидентуры, которая сохраняется до настоящего времени.

Не менее известны работы W. Halsted по эндокринной хирургии. Он располагал огромным опытом оперативного лечения зоба, гиперпаратиреоза. Его монография «The operative story of goiter. The authors operation» (1920) являлась настольным пособием по тиреоидной хирургии нескольких поколений хирургов. W. Halsted также детально описал топографию паращитовидных желез и их кровоснабжение. В частности, было установлено наличие единственной артериальной веточки, раздельно снабжающей нижние паращитовидные железы и повреждение которых часто приводит к развитию гипопаратиреоза. W. Halsted впервые начал практиковать пересадки фрагментов паращитовидных желез при гипопаратиреозе и установил исходное значение гормонального дефицита для успеха трансплантаций.

Широко известны работы W. Halsted по применению регионарной анестезии. Он был большим поборником асептики, предложил пользоваться резиновыми перчатками при операциях. W. Halsted был большим другом T. Kocher, неоднократно посещал его клинику, присутствовал при операциях. Ему принадлежит одно интересное наблюдение. Сравнивая методики операций Т. Kocher и T. Bilroth, W. Halsted отмечал, что у первого чаще наблюдались случаи послеоперационного гипотиреоза, а у второго - гипопаратиреоза. Подобное явление W. Halsted объяснил особенностями техники оперативных вмешательств, выполняемых каждым из них: T. Kocher оперировал медленно, тщательно удалял всю видимую ткань железы, следствием чего были частые случаи гипотиреоза; T. Bilroth оперировал 
Лекції

быстро, захватывал в зажимы большие участки ткани железы, меньше заботился о гемостазе, в результате чего возникали условия для повреждения паращитовидных желез.

В Балтиморе H. Cushing познакомился и сблизился с известным терапевтом, историком медицины, одним из основателей и руководителем медицинской службы John Hopkins Hospital W. Osler (1849-1919). W. Osler являлся одной из наиболее выдающихся фигур в американской и мировой внутренней медицине конца XIX и начала XX века. Им были детально изучены и описаны многие внутренние заболевания, обнаружены новые симптомы, которые теперь носят его имя, предложены новые методы диагностики.

Особый интерес W. Osler концентрировался на вопросах неврологии. Из 1400 его публикаций более 200 были посвящены вопросам неврологии. W. Osler подчеркивал и всячески поддерживал выделение нейрохирургии в качестве отдельной специальности. Со временем между W. Osler и H. Cushing возникли тесные дружеские отношения. Они особенно упрочились после того, как Н. Cushing принимал участие в операции его сына, получившего на фронте смертельное ранение в живот. Эта дружба способствовала формированию молодого, активного врача в зрелого ученого с высоким уровнем клинического мышления и профессионального мастерства [10-12].

В то время в John Hopkins Hospital были приглашены известные, крупные ученые и практики - патологоанатом W. Welsh и H. Kelly, возглавивший кафедру акушерства. Под влиянием их и еще некоторых старших коллег творческая активность и колоссальная работоспособность Н. Cushing получили успешное развитие и приложение в его научно-практической деятельности в течение последующих многих лет [3, 4, 13-15].

К этому времени относится зарождение y H. Cushing под влиянием W. Osler интереса к истории медицины. От простого собирательства медицинских книг он перешел к систематическому изучению истории медицины, в чем немало преуспел в последующие годы. В этом начинании его поддержал отец, который прислал в Балтимор много своих медицинских книг, в том числе из библиотеки деда и прадеда.
Период прохождения резидентуры в Балтиморе сопровождался дальнейшим совершенствованием хирургического мастерства H. Cushing и активным участием в выполнении ряда научных программ. В частности, он занимался изучением метода регионарной анестезии путем «кокаинизации» периферических нервных стволов, активно продолжал внедрять рентгенологические методы исследования при различных заболеваниях.

Участвуя в эвакуации раненых с Кубы во время Американско-испанской войны 1898 г, H. Cushing получил опыт военно-полевой хирургии, заинтересовался клиникой и лечением прободных язв кишечника при брюшном тифе, провел ряд бактериологических исследований, выяснил роль инфекции во вторичной перфорации пищевода при брюшном тифе. Результатом явилось опубликование нескольких научных статей. Совместно с коллегой Н. Livingood H. Cushing изучал влияние голодания на микробную обсемененность желудка и тонкого кишечника: они установили, что применение этого режима благоприятно влияет на исходы абдоминальных операций [14]. Он также занимался изучением болезни Рейно, вопросами анестезиологии, впервые успешно зашил ранение грудного лимфатического протока.

По рекомендации и с помощью W. Osler H. Cushing после завершения обучения в резидентуре в 1900-1901 гг. совершил 14-месячное европейское турне, в ходе которого посетил ряд ведущих мировых клиник и лабораторий [16] В Берне, в хирургической клинике Т. Kocher, мастерство которого в области тиреоидной хирургии произвело на Н. Cushing неизгладимое впечатление, он совместно с H. Kronecker изучал вопросы взаимосвязи артериального давления, в основном систолического, с внутричерепным давлением и установил, что повышение артериального давления играет защитную роль, усиливая кровоснабжение мозга. Результаты этой работы подтолкнули его к выявлению и описанию рефлекса (триады) Кушинга [16, 17].

Тогда же Н. Cushing занимался исследованием влияния на организм физиологического раствора. В Англии в лаборатории Ch. Sherrington он участвовал в исторических опытах по определению локализации 
двигательных центров коры головного мозга [18]. Интересным и полезным оказался визит в Италию, где Н. Cushing познакомился с изобретателем ртутного манометра для измерения артериального давления S. Riva-Rocci. Сделав подробные тщательные зарисовки устройства прибора, Н. Cushing стал активным сторонником внедрения его в клиническую практику, хотя на первых порах это начинание не встретило поддержки [3, 4].

В октябре 1901 г. Н. Cushing возвращается в Балтимор, в John Hopkins Hospital, где из ученика превращается в учителя. W. Halsted предлагает ему пост Associate Surgeon со специализацией по хирургии нервной системы. Одним из успешных достижений Н. Cushing в этот период явилась организация им Old Hunterian Experimental Surgical Laboratory. Это была учебная лаборатория, где студенты имели возможность изучать топографическую анатомию, оперативную хирургию, заниматься физиологическими исследованиями, оперировать на животных, отрабатывать элементы хирургической техники. Позднее, работая в Harvard Medical School, он создал аналогичную лабораторию, где продолжил педагогическую деятельность [19-21].

В 1902 г. Н. Cushing женился на Katrin Stoun Crouwell, девушке с которой они вместе росли в Кливленде. У них родилось пятеро детей, один из которых, старший сын Williams погиб в 26-летнем возрасте в автомобильной катастрофе. В семье Н. Cushing были заведены порядки, как в доме его отца. Глава семьи много работал, большую часть времени проводил в клинике, оперировал, писал научные рабоы. Домашнее хозяйство и воспитание детей было возложено в основном на супругу. Дом отличался гостеприимством, его посещали с удовольствием коллеги, студенты [3. 4].

В течение последующих нескольких лет после возвращения из Европы Н. Cushing серьезно заинтересовался нейрохирургией, начал оперировать возрастающее количество больных с опухолями головного мозга и, в частности, гипофиза. Постепенно он стал ведущим, наиболее квалифицированным специалистом в этой области, придав нейрохирургии характер самостоятельного направления клинической хирургии, т.е. стал одним из ее основоположников. W. Osler писал: «Harvey Cushing открыл новую страницу в хирургии». А известный его биограф M. Bliss отмечал: «Cushing собственноручно перенес нейрохирургию из каменного века в состояние, которое соответствует современной практике» [4, 17].

В 1906 г. Н. Cushing произвел одну из первых своих операций 14-летней девочке, у которой наблюдались головные боли, расстройства зрения, ожирение, гипоплазия наружных половых органов. Была выполнена декомпрессионная трепанация черепа. В связи с отсутствием эффекта аналогичная операция была сделана с противоположной стороны. Больная умерла. При аутопсии была обнаружена большая киста гипофиза. До Н. Cushing австрийский невропатолог A. Froehlich описал 5-летнего мальчика с аналогичной картиной заболевания. Его оперировал австрийский хирург A. Eiselsberg, который обнаружил и дренировал опухоль гипофиза. Данная патология получила наименование - синдром Froehlich, а позднее Froehlich-Babinski. J. Babinski, французский невропатолог польского происхождения, описал этот синдром годом ранее [22, 23].

В 1909 г., продолжая накапливать опыт нейрохирургических операций, H. Cushing произвел вторую в мире операцию по поводу аденомы гипофиза с синдромом акромегалии. Первая была выполнена австрийским хирургом H. Schloffer в 1907 г. Больной, 38-летний фермер, был направлен к Н. Cushing из Мауо Clinic. Доступ был выполнен через пластинку фронтальной пазухи и была удалена аденома передней доли гипофиза. Больной выздоровел и прожил еще 21 год. В течение последующих трех лет Н. Cushing наблюдал 46 больных с заболеваниями гипофиза, большинство из которых были оперированы. Следует отметить, что в то время подобные вмешательства относились к разряду наиболее сложных и тяжелых. По статистике два из трех больных умирали после таких операций. H. Cushing значительно усовершенствовал технику операций на гипофизе, разработал ряд новых приемов и усовершенствований, в результате смертность при подобных вмешательствах значительно снизилась [24, 25].

Последние годы пребывания Н. Cushing в John Hopkins Hospital сопровождалось почти полным переходом на позиции нейрохирургии. Он много и успешно оперирует по 
Лекції

поводу опухолей головного мозга, гипофиза, обучает своих помощников, пишет многочисленные, обширные научные работы. Например, когда в 1907 г. W. Keen предложил ему написать для пятитомного руководства по хирургии 80-страничную главу, Н. Cushing представил рукопись из 800 страниц с двумястами собственноручно выполненных иллюстраций. В следующем году эта работа была опубликована как отдельная монография в 276 страниц со 154 иллюстрациями [16, 21]. Ее появление окончательно утвердило в медицинском мире позиции Н. Cushing, как лидера и создателя нового направления в хирургии - нейрохирургии.

В 1910 г., отвергнув многочисленные предложения из нескольких Университетов занять должность главного хирурга, в том числе из его alma mater Yale University, H. Cushing перебрался в Бостон. Здесь он получил должность профессора хирургии в Harvard Medical School и главного хирурга недавно созданного Peter Bent Brigham Hospital. На этих постах он оставался до 1932 г., до времени выхода на пенсию.

В эти годы Н. Cushing, помимо активной хирургической и научной деятельности, занимался подготовкой специалистов-нейрохирургов. В течение 1911-1932 г. он возглавлял резидентуру по нейрохирургии и подготовил 22 квалифицированных хирургов, которые со временем заняли профессорские должности в ряде клиник страны [14, 15]. Одним из его наиболее талантливых учеников, впоследствии ставшим крупнейшим нейрохирургом Америки, был W. Dandy, который предложил классические методики вентрикулографии, вентрикулопункции, пневмоэнцефалографии, разработал ряд новых нейрохирургических операций, носящих его имя, описал ряд новых симптомов неврологических заболеваний.

C началом Первой мировой войны H. Cushing возглавил Harvard Medical Regiment и в 1915 г. отправился в Европу, где развернул свою деятельность в одном из госпиталей в предместьях Парижа. Он возглавлял службу оказания помощи раненым в голову. Работа была сложная, тяжелая, ответственная. Каждый врач должен был обслуживать до 80 раненных. Сам Н. Cushing выполнял 7-8 краниотомий в день. В этот период он разработал классификацию травм черепа, которой пользуются до настоящего времени, внес ряд усовершенствований в методики обработки ран.

В 1917-1918 гг. Н. Cushing возглавлял военный госпиталь. К концу службы он заболел так называемым в то время сосудистым полиневритом, известным сейчас, как синдром Gullian-Barre. К нему присоединились признаки окклюзии бедренных артерий и хромота. Так как H. Cushing был «тяжелым» курильщиком, то эти заболевания преследовали его до конца жизни. Положение усугубилось возникшей конфликтной ситуацией. Военная цензура перехватила его письмо к жене, в котором он позволил себе ряд критических высказываний в адрес английской администрации, в частности одного из врачей. Назревал разбор и угроза военного трибунала, но Н. Cushing перевели из подчинения британской в американскую администрацию и вскоре он вернулся в США. В 1936 г. он написал книгу воспоминаний о своей службе военным хирургом «Memoranda during the war» [3, 15, 26-28].

Вернувшись в Harvard Medical School H. Cushing продолжил активную хирургическую деятельность, оперировал сотни

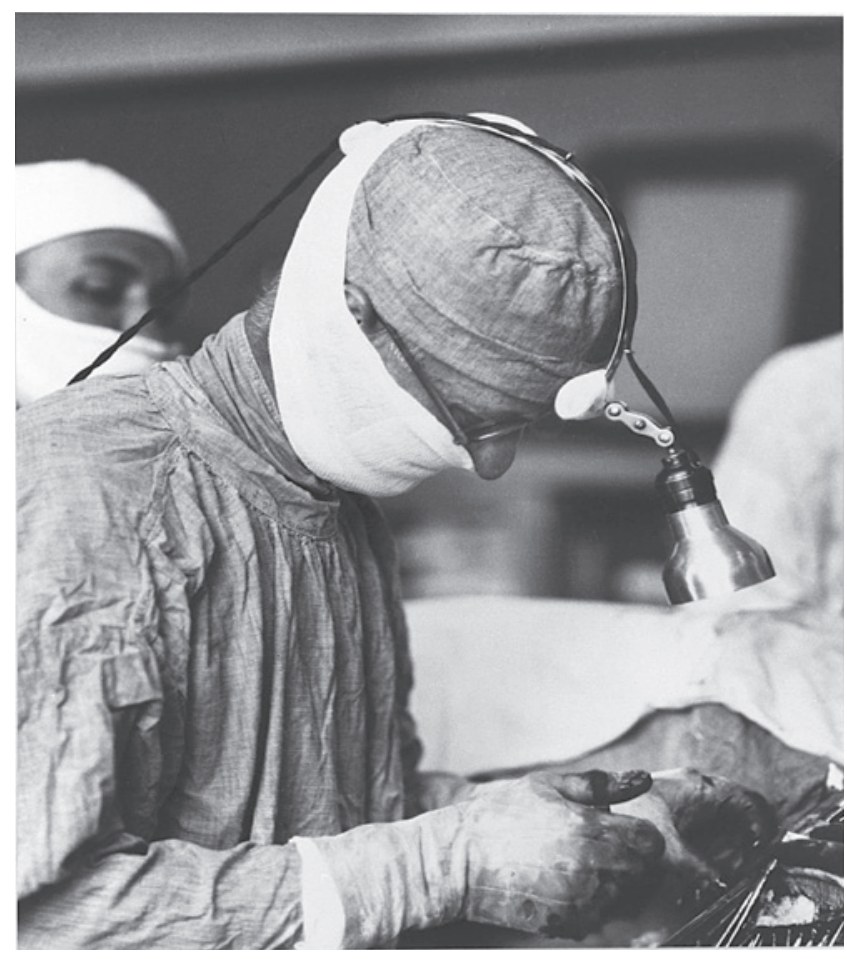

Фото 2. Х. Кушинг в операционной

Photo 2. H. Cushing in the operation room 
общехирургических и нейрохирургических больных.

H. Cushing внес многочисленные усовершенствования и новые технические приемы при выполнении операций. В частности, в то время кровотечения являлись самым серьезным осложнением операций на головном мозге и служили причиной многочисленных неблагоприятных исходов. Н. Cushing предложил оригинальные серебряные клипсы, с помощью которых удавалось успешно справляться с этим грозным осложнением. Им был предложен новый транссфеноидальный доступ к гипофизу. Работая совместно с физиком W. Bowie, они создали специальное устройство для определения локализации кровотечений, возможности подхода к ним и использования электрокоагуляции, а также специальный отсос для удаления скоплений крови в ране и облегчения гемостаза.

H. Cushing оперировал не торопясь, очень тщательно с ювелирной точностью, уделяя внимание любым, даже самым мелким деталям, что в сочетании с усовершенствованными методами обезболивания обеспечивало благоприятные исходы его операций. Следует отметить еще одно его качество, как тонкого диагноста: зачастую он мог по характеру клинической картины, не прибегая к рентгенисследованию и другим вспомогательным методам, четко установить наличие и локализацию опухоли мозга, возможности ее удаления и прогноз [3, 4, 6, 15].

Период 20-х и начала 30-х гг. явился наиболее благотворным в деятельности H. Cushing. Помимо активной лечебной, административной деятельности им были выполнены и описаны результаты ряда исследований. Все это сочеталось с активной педагогической работой. Так, в 1918-1928 г. Н. Cushing написал 6 книг, свыше 100 научных статей и множество отчетов. Анализ показал, что для выполнения указанного объема научной продукции он должен был писать не менее 10000 слов в день [28].

В эти годы H. Cushing выполнил историческое исследование гипофизарной патологии, высказал ряд оригинальных, приоритетных положений в эндокринологии и нейрохирургии, написал монографию о питуитарном базофилизме и узаконил клиническое существование синдрома, носящего его имя и обессмертившего его в истории медицины.

По своим характерологическим данным H. Cushing был доброжелательным, сдержанным, воспитанным человеком, приветливым и внимательным к своим больным и окружающим, но, как ни странно, менялся в рабочих условиях. Он был требовательным руководителем, жестким, временами несдержанным в операционной, но после подобных вспышек мог извиниться. Сохранились воспоминания одного из его учеников F. Newell, ставшего впоследствии профессором акушерства в Harward Medical School, который писал: «...работать с ним было крайне тяжело и подчиненным и начальству. ... Его ужасные амбиции не давали ему позволить кому-либо выполнить работу раньше». Другой его коллега C. Jacobsen, пытаясь характеризовать Н. Cushing как ученого, отмечал: «Как у ученого у него был дедуктивный склад ума. Некоторые исследователи собирают материал и затем, исходя из полученных данных, пытаются сделать выводы. Он же сначала создавал теорию, а затем прилагал все усилия и изобретательность, чтобы найти подтверждения этой теории на практике» [15].

Результаты хирургической деятельности H. Cushing впечатляют. Фактически он создал и утвердил в хирургии новое направление нейрохирургию, и разработал основные принципы и методики многих оперативных вмешательств при различных формах патологии, в частности при опухолях головного мозга. В то время лишь немногие хирурги решались оперировать при заболеваниях головного мозга, т.к. подобные операции сопровождались почти $90-100 \%$ смертностью.

Благодаря кропотливым научным исследованиям и практической разработке хирургических основ церебральной патологии H. Cushing удалось добиться невиданных успехов и снизить смертность при операциях по поводу опухолей мозга во много раз. К концу жизни им было выполнено свыше 2000 подобных операций. Его пациентами были представители различных слоев общества как США, так и других стран. Например, в 1910 г. он оперировал генерала L. Wood, начальника штаба армии США, и удалил у него менингеому больших размеров. Генерал выздоровел, через месяц вернулся к выполнению своих 
Лекції

обязанностей, а в последующем участвовал в Первой мировой войне и стал губернатором Филиппин.

Список научных трудов H. Cushing насчитывает 13 монографий и свыше 300 статей [15]. Полная библиография его трудов была опубликована в 1939 г. Обществом имени H. Cushing и хранится в библиотеке Королевской хирургической коллегии в Лондоне. Можно лишь упомянуть некоторые наиболее значимые работы: «Surgery of the head» (1908), «Some aspects of the pathological physiology of intracranial tumors» (1909), «Tumors of the nervus acusticus and the syndrome of the cerebello - pontile» (1917), «The life of Sir William Osler», 2 vol. (1925), «A classification of the tumors of the gliomz group on a gistogenic basis» (1926), «Tumors arising from the blood vessels» (1928), «Intracranial tumors» (1932), «Meningiomas. Their classification, regional behavior, life histoty and surgical end results» (1938) и др. Особняком следует выделить две работы, которые можно рассматривать как этапные в научно-практической деятельности H. Cushing и знаменующие начало и завершение изучения патологии гипофиза. Это монографии «The pituitary body and its disorders. Clinical states produced by disorders of the hypophysis cerebry» (1912) и «The basophile adenomas of the pituitary body and their clinical manifestation (pituitary basophilism)» (1932), которые окончательно утвердили мировую известность Н. Cushing, как выдающегося нейрохирурга и эндокринолога.

У многих представителей медицинского мира имя Н. Cushing ассоциируется с прогрессом эндокринологии, его работами по патологии гипофиза, известным описанием синдрома глюкокортикоидного гиперкортицизма, который получил наименование - синдром Кушинга. В действительности следует признать, что первой и основной сферой его деятельности была нейрохирургия, основателем которой он явился и в высокой степени способствовал ее успехам в научном и практическом плане. Единственное, что может примирить эндокринологов с этим фактом, является то, что значительная часть научных исследований и практической деятельности Н. Cushing была связана с изучением центральной и основной эндокринной железы - гипофиза.
Интерес Н. Cushing к гипофизу не ослабевал на протяжении всей его жизни. Его личная секретарша Madeline Stanton записывала в своем дневнике: «гипофиз ... это была его первая и единственная настоящая любовь» [19]. Выполненные им в начале 1900-х гг. несколько десятков операций по поводу акромегалии сопровождались не только отличными хирургическими результатами, но и отчетливыми соматическими сдвигами в состоянии пациентов, что косвенно свидетельствовало о какихто ранее неизвестных функциях гипофиза. Об этом Н. Cushing сообщил в пространном докладе на сессии Американской ассоциации хирургов в 1909 г.

Оперируя своих больных, Н. Cushing параллельно выполнил ряд исследований, которые составили бы честь любому патофизиологу. В частности, в эксперименте на собаках он показал, что гипофиз является жизненно необходимой железой и после его удаления животные погибали. Он так же описал транзиторное увеличение щитовидной железы, надпочечников и гонад после удаления гипофиза, которое сменялось атрофическими изменениями Тогда же Н. Cushing высказал мысль, что наличие опухоли в эндокринной железе, в частности в гипофизе, позволяет приблизиться к представлениям о нарушениях ее функций. Наблюдая клиническое улучшение у больных с акромегалией после удаления ацидофильной аденомы, он высказал предположение, что эти клетки выделяют какой-то ростовой фактор, предвосхитив открытие гормона роста [3].

На определенном этапе у Н. Cushing проявился интерес к щитовидной железе. В литературе появились сообщения о лечении последствий удаления железы экстрактами из ее ткани. Кстати, большим сторонником этого метода был его старший товарищ W. Osler. Выполнив некоторое количество тиреоидных операций и убедившись в эффективности заместительной терапии, H. Cushing попытался перенести «тиреоидную модель» на гипофиз и предположил, что последний вырабатывает 1-2 гормона, влияющих на метаболизм и половое развитие. Он попробовал лечить больных после гипофизэктомии соответствующими экстрактами, но потерпел неудачу. Больному мальчику после удаления гипофиза по поводу опухоли ввели экстракт гипофизарной ткани. Эффекта не 
было. Больной умер. Тогда же Н. Cushing ввел понятие «диспитуитаризм».

Не добившись успеха с трансплантациями гипофиза, H. Cushing охладел на некоторое время к эндокринологии и даже иногда называл ее «эндокриминология». Тем не менее, в 1917 г. он был избран Президентом общества по изучению внутренней секреции и в последующие годы оставался сторонником концепции полифункциональной роли гипофиза в организме [29].

Дальнейшее экспериментальное и клиническое изучение физиологии и патологии гипофиза, разработка методов хирургического лечения ряда его заболеваний завершилось в 1932 г. изданием H. Cushing классической, упоминаемой выше монографии. В ней, помимо описания синдрома глюкокортикоидного гиперкортицизма, получившего его имя, Н. Cushing высказал ряд соображений и выводов по поводу вариантов и механизмов развития патологии гипофиза. Интересно отметить, что в 1898 г. W. Osler описал симптомокомплекс, подобный синдрому Кушинга, но трактовал его как микседему [3, 4, 30-35].

Заслуживает внимания еще одна сторона деятельности H. Cushing. С детства он увлекался рисованием и проявил немалые способности. Он собирал различные растения, минералы, насекомых и делал прекрасные зарисовки, которыми затем украшал письма друзьям. Это увлечение продолжилось в период дальнейшей учебы. В своем рабочем дневнике он рисовал очень близко к оригиналу различных людей, больных, гистологические препараты, отдельные этапы операций.

В период работы в John Hopkins Hospital в Балтиморе Н. Cushing познакомился с Max Brödel, одним из крупнейших медицинских иллюстраторов в США. Последний был выходцем из Лейпцига, где получил классическое художественное образование и широкую международную известность, как иллюстратор. Эмигрировав в США, M. Brödel сотрудничал со многими выдающимися учеными и принимал участие в подготовке и оформлении их трудов. B John Hopkins Hospital oн организовал Department of Art as Applied to Medicine, в котором занимался иллюстрированием медицинских работ различного профиля.

H. Cushing посещал проводимые M. Brödel занятия, который сразу отметил большие способности ученика. Постепенно они сблизились и стали друзьями. Следует отметить, что каждый из них испытал взаимное влияние на свое творчество. В качестве примера можно напомнить 276-страничную монографию «Surgery of the head», которая, как упоминалось выше, содержала 154 отличных, высоко художественных иллюстраций, выполненных лично автором [15, 26, 36, 37].

Помимо способностей талантливого художника H. Cushing был от природы награжден писательским даром. Он оставил многочисленные литературные зарисовки с описаниями людей, с которыми встречался, и событий, в которых участвовал. В частности, представляют интерес его записки, сделанные во время испанско-американской и первой мировой войн. С интересом, как маленькие новеллы, читаются его протоколы операций, отдельные фрагменты подготавливаемых книг.

Для стиля H. Cushing была характерна свободная манера изложения, хороший язык, способность выделить основные моменты в характеристиках людей и событий, о которых писал. В наиболее полной мере его литературные способности проявились в написанной и опубликованной в 1925 г. двухтомной биографии своего учителя и друга «The Life of Sir William W. Osler» [38]. За эту работу H. Cushing был награжден Пулитцеровской премией, одной из наиболее престижных премий, присуждаемых в США за работы в области художественной литературы и журналистики.

Заслуживают упоминания встречи H. Cushing с великим русским физиологом И.П. Павловым на Международном конгрессе физиологов (1929) в Бостоне [3]. И.П. Павлов, занимаясь много лет проблемами высшей деятельности, естественно, заинтересовался операциями на головном мозге, выполняемыми выдающимся нейрохирургом. В один из дней Н. Cushing организовал для И.П. Павлова показательную операцию в своей клинике. Больному с большой опухолью левого полушария под местной анестезией блестяще было произведено удаление новообразования. И.П. Павлов был восхищен мастерством хирурга. В свою очередь, Н. Cushing был поражен любознательностью, активностью 80-летнего ученого. Их вторая встреча состоялась в лаборатории W. Cannon во время лекции 
Лекції

И.П. Павлова об эффектах бромидов при экспериментальных неврозах. И вновь Н. Cushing был восхищен ясностью мышления и подвижностью великого ученого.

C ранней молодости Н. Cushing был заядлым книголюбом и это увлечение он пронес через всю жизнь. У его отца была хорошая медицинская библиотека, в которой было много старинных книг по медицине, принадлежавших его предкам, и которую он передал сыну. Интересы Н. Cushing были чрезвычайно разнообразны: в его библиотеке были представлены многочисленные книги по медицине, истории, астрономии, физике, искусству. Большое внимание H. Cushing уделял истории медицины, в частности, книгам о великом анатоме и хирурге XVI века Andreas Vesalius, о котором написал большое исследование [39]. К концу жизни библиотека H. Cushing насчитывала более 8000 томов. В 1933 г. он передал ее в дар Yale University. Так же он уговорил поступить своих друзей J. Fulton и A. Klebs, обладавших большими книжными собраниями. В результате библиотека Yale University стала крупнейшей среди медицинских библиотек мира [39-41].

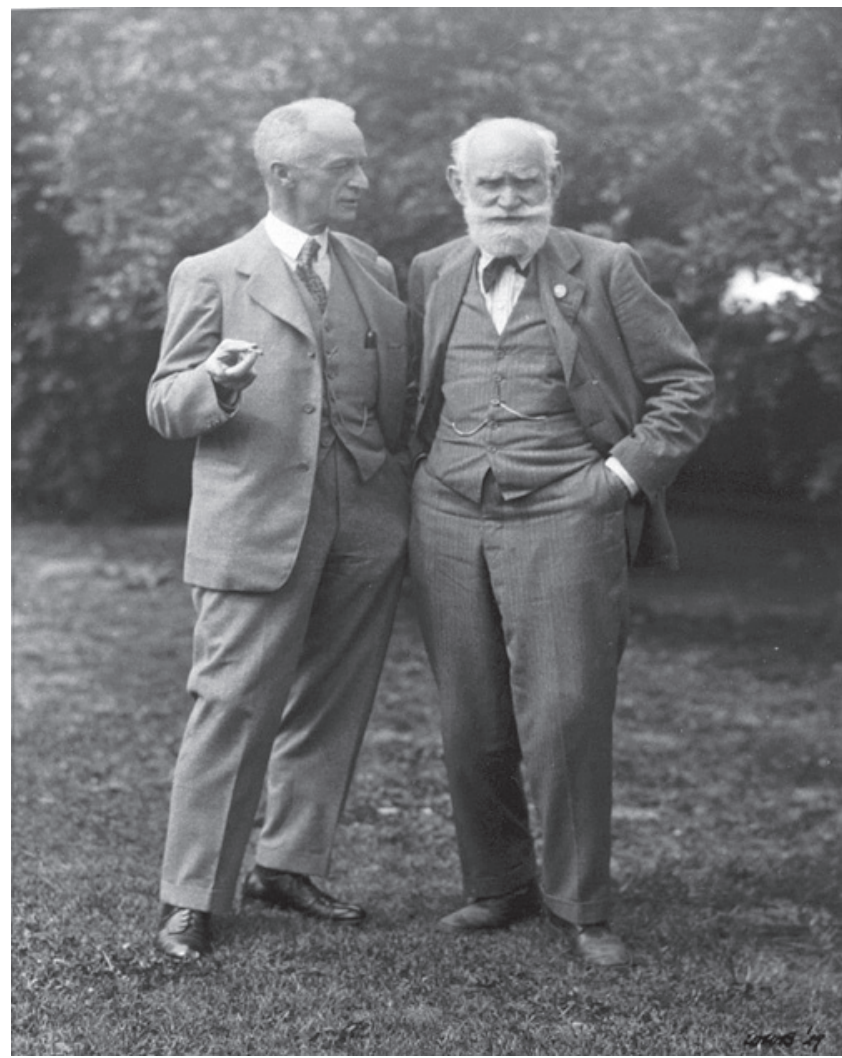

Фото 3. Х. Кушинг и И.П. Павлов

Photo 3. H. Cushing and I.P. Pavlov
В 1932 г. Н. Cushing прекратил свою хирургическую деятельность, оставил должности в Harvard Medical School и Piter Bent Birgham Hospital и переехал в Нью-Хейвен поближе к Yale University, где он получил пост профессора неврологии и оставался до 1937 г. В этот период H. Cushing приводит в порядок свои архивы, отдельные записи, рисунки, военные заметки, доклады и часть этого оформляет в виде книги воспоминаний, окончательно дорабатывает и редактирует одну из своих наиболее выдающихся монографий «Meningeomas». Параллельно Н. Cushing paботает над капитальной «Bio-Bibliography of Andreas Vesalius», которая вышла в свет после его смерти в 1943 г. [42-45].

Поистине титанической работой $\mathrm{H}$. Cushing было создание Регистра опухолей головного мозга, который содержал практически все данные более 2000 оперированных им больных. Он включал образцы удаленных опухолей, гистологические препараты опухолей, мозг умерших больных, данные историй болезни, зарисовки, более 1500 фотонегативов.

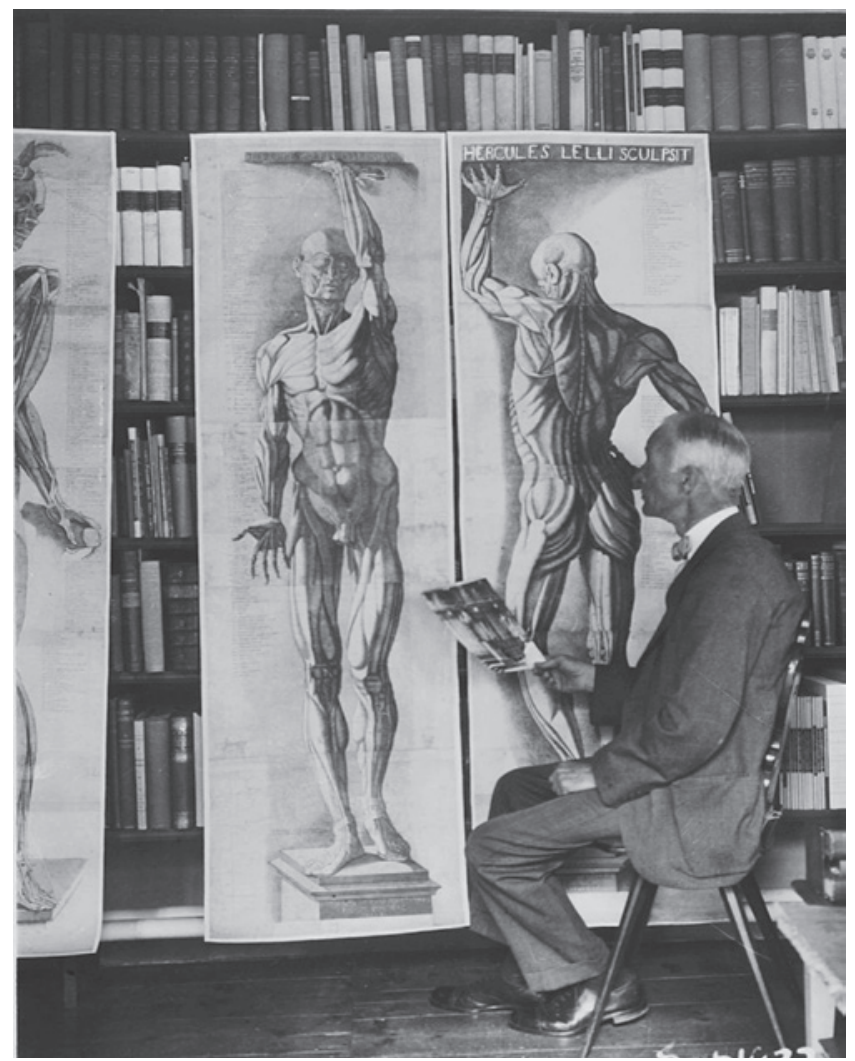

Фото 4. Х. Кушинг в своей библиотеке

Photo 4. $H$. Cushing in his library 


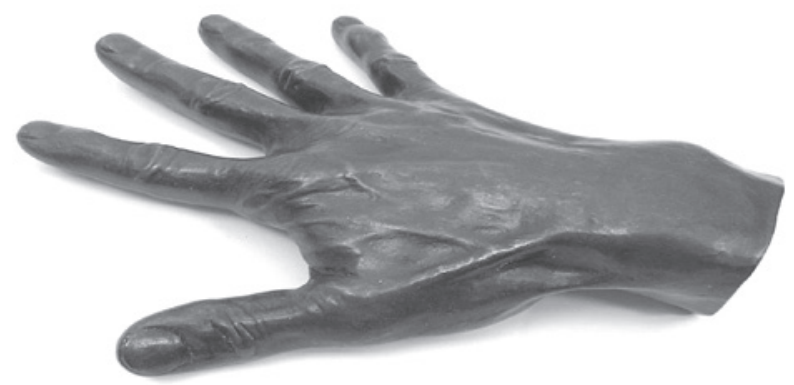

Фото 5. Бронзовый слепок кисти Х. Кушинга

Photo 5. Bronze cast of the H. Cushing's hand

Еще одним из увлечений Н. Cushing было создание коллекции гипсовых слепков кистей рук выдающихся хирургов, посещавших его клинику; там же хранился и его собственный слепок, воспроизведенный в бронзе [3, 13].

Успехи и достижения Н. Cushing были отмечены многочисленными почетными званиями и наградами, перечисление которых заняло бы несколько страниц. Он был Почетным членом 9 американских и 13 зарубежных университетов, награжден орденами и медалями нескольких стран, отмечен многочисленными премиями, состоял почетным членом более 60 научных обществ Америки, Европы, Азии, был членом редколлегии боле 70 журналов и пр. В 1932 г. 35 его коллег, среди которых было много его учеников, организовали Научное Общество нейрохирургов им. Harvey Cushing. В настоящее время оно превратилось в Американскую ассоциацию нейрохирургов, насчитывающую более 1000 членов.

H. Cushing ушел из жизни 7 октября 1939 г. в возрасте 70 лет. Причиной смерти послужил обширный инфаркт миокарда, который начал развиваться 3 октября после того, как он поднял увесистый том трудов Vesalius. В течение последующих 3-х дней состояние Н. Cushing прогрессивно ухудшалось, развивались признаки ослабления сердечной деятельности, брадиаритмия. В 2 часа утра 7 октября наступила остановка сердца. При аутопсии были выявлены: окклюзия задней коронарной артерии, полная окклюзия обеих бедренных артерий и, в подтверждение поверия, что доктора болеют теми же болезнями, которые лечат, была обнаружена коллоидная киста в полости третьего желудочка мозга диаметром 1 см. Урна с прахом Н. Cushing захоронена на кладбище в Кливленде рядом с могилами его родителей, братьев и сына [46].
Чтобы не завершать данное сообщение на минорной ноте, хотелось бы привести оптимистическую выдержку из доклада H. Cushing на Первом неврологическом конгрессе 31.08.1931 г. в Берне, где он делал первые шаги в хирургии в 1900-1901 гг. [47]. H. Cushing привел окончательную статистику своих 2023 операций на головном мозге. В ней было указано, что смертность после операций по поводу глиом мозга снизилась с 30,9\% до $11,1 \%$, аденом гипофиза - с 13,5\% до 5,7\%, менингеом - с 21,0\% до 7,7\%. Заключая свое сообщение, он сказал: «Этот доклад, который, очевидно, последний об опухолях мозга, нельзя завершить, не воздав должного моим ассистентам и сотрудникам, которые выполнили всю тяжесть работы и разделили ответственность». Обращаясь к присутствующм нейрохирургам, своим многочисленным ученикам, H. Cushing закончил свое выступление словами Леонардо да Винчи - «... плох тот ученик, кто не превзойдет своего учителя», но это, как говорили братья Стругацкие, это уже совсем другая история.

\section{Список использованной литературы}

1. Рибаков СЙ. Про історію хвороби Іценка-Кушінга. Клінічна ендокринологія та ендокринна хірургія. 2014;47(2):7683. (Rybakov S. On the history of Cushing's disease. Clinical Endocrinology and Endocrine Surgery. 2014;47(2):76-83)

2. Рибаков СЙ. Випадок хвороби Іценка-Кушинга (історична мініатюра). Клінічна ендокринологія та ендокринна хірургія. 2014;48(3):58-64. (Rybakov S. The case of Itsenko-Cushing's disease (historical miniature). Clinical Endocrinology and Endocrine Surgery. 2014;48(3):58-64)

3. Fulton JF. Harvey Cushing - a Biography. Oxford: Blackwell; 1946. $754 \mathrm{p}$.

4. Bliss M. Harvey Cushing: A Life in Surgery. Oxford: Oxford University Press; 2005. 610 p.

5. Beecher HK. The first anesthesia records (Codman, Cushing). Surg Gynecol Obstet. 1946;71:689-693.

6. Hirsch NP, Smith GB. Harvey Cushing: his contribution to anesthesia. Anesth Analg. 1986 Mar;65(3):288-93

7. Wright AJ. Early use of the Cushing-Codman anesthesia record. Anesthesiology. 1987 Jan;66(1):92.

8. Fulton JF. Harvey Cushing and roentgenology. Amer J Roentgenol. 1939;41:1020-1.

9. Rankin JS. William Stewart Halsted: a lecture by Dr. Peter D. Olch. Ann Surg. 2006 Mar;243(3):418-25.

10. Duffy T. The Osler-Cushing covenant. Perspect Biol Med 2005;48(4)592-602.

11. Feindel W. Osler and the «medico-chirurgical neurologists»: Horsley, Cushing, and Penfield. J Neurosurg. 2003 Jul;99(1):188-99.

12. da Mota Gomes M. William Osler and Harvey Williams Cushing: Friendship Around Neurosurgery. Ann Indian Acad Neurol. 2019 Oct-Dec;22(4):384-388.

13. Moore FD. Harvey Cushing. General surgeon, biologist, professor. J Neurosurg. 1969 Sep;31(3):262-70.

14. Sweet WH. Harvey Cushing: author, investigator, neurologist, neurosurgeon. J Neurosurg. 1979 Jan;50(1):5-12.

15. Shin P. Harvey Cushing's ghosts: death and hauntings in modern 
Лекції

medicine. Yale J Biol Med. 2011 Jun;84(2):91-101.

16. Modlin IM, Shin JH. Harvey Cushing: first guest at «The Divine Banquet of the Brayne». Surgery. 1993 Apr;113(4):438-55.

17. Greenblatt SH. The crucial decade: modern neurosurgery's definitive development in Harvey Cushing's early research and practice, 1900 to 1910. J Neurosurg. 1997 Dec;87(6):964-71.

18. Pendleton C, Zaidi HA, Chaichana KL, Raza SM, Carson BS, CohenGadol AA, Quinones-Hinojosa A. Harvey Cushing's contributions to motor mapping: 1902-1912. Cortex. 2012 Jan;48(1):7-14.

19. Feindel W. Harvey Cushing - a standard worth striving for. CMAJ. 2006 Jun 6;174(12):1748-9.

20. Tilney NL. Harvey Cushing and the surgical research laboratory. Surg Gynecol Obstet. 1980 Aug;151(2):263-70.

21. Long DM. Harvey Cushing at Johns Hopkins. Neurosurgery. 1999 Nov;45(5):983-9.

22. Fröhlich A. Ein Fall von Tumor der Hypophisis cerebri ohne Akromegalie. Wien Klin Wochenschr. 1901;15:883-6,906-8.

23. Cushing H. Sexual infantilism with optic atrophy in cases of tumor affecting the hypophysis cerebri. J Nerv Ment Dis. Chicago. 1906;33(11):704-16.

24. Cushing H. III. Partial Hypophysectomy for Acromegaly: With Remarks on the Function of the Hypophysis. Ann Surg. 1909 Dec;50(6):1002-17.

25. Cushing H. Weir Mitchell lecture: Surgical experience with pituitary disorders. JAMA. 1914;63:1515-25.

26. Thomson EH. Harvey Cushing: Surgeon, Author, Artist. New York: Henry Schuman; 1950. 347 p.

27. Lepore FE. Harvey Cushing, Gordon Holmes, and the neurological lessons of World War I. Arch Neurol. 1994 Jul;51(7):711-22.

28. Horwitz NH. Library: historical perspective. Harvey Cushing (1869-1939). Neurosurgery. 1996 Nov;39(5):1062-7.

29. T. Sawin C. Harveey Cushing and «Endo - Criminology.» Endocr. News. 2007 Aug;32(8):34-36/

30. Bauer J. The so-called Cushing's Syndrome, its History, Terminology and Differential Diagnosis. Acta Med Scand. 1950;137(6):411-6.

31. Medvei VC. The history of Cushing's disease: a controversial tale. J R Soc Med. 1991 Jun;84(6):363-6.

32. Lindholm J. Cushing's syndrome: historical aspects. Pituitary. 2000 Oct;3(2):97-104.

33. Aron DC. The path to the soul: Harvey Cushing and surgery on the pituitary and its environs in 1916. Perspect Biol Med. 1994 Summer;37(4):551-65.

34. Aron DC. Cushing's syndrome from bedside to bench and back: a historical perspective. Endocrinol Metab Clin North Am. 2005 Jun;34(2):257-69, vii.
35. De P, Evans L, Scanlon M. a.al. «Osler's phenomenon» misdiagnosed Cushing's syndrome. Postgrad Med J. 2003;79:594-6.

36. Udelsman R. Presidential address: Harvey Cushing: the artist. Surgery. 2006 Dec;140(6):841-6.

37. Jay V. The legacy of Harvey Cushing. Arch Pathol Lab Med. 2001 Dec;125(12):1539-41.

38. Cushing H. The Life of Sir William Osler, volume 2. Oxford: Clarendon Press; 1925. 1413 p.

39. Baumgarthner L. Harvey Cushing as a book collector and litterateur. Bull Hist Med. 1940:8:1055-66.

40. Fulton JF. Harvey Cushing and Arnold Clebs: Their friendship and their libraries. Bull Hist Med. 1947;21:512-23.

41. Holman E. Sir William Osler and Harvey Cushing: Two great personalities and medical bibliophiles. Stanford Med Bull. 1961;19:173-85.

42. Jefferson G. Harvey Cushing and his books. J Hist Med. 1943;1:246-53

43. Fulton JF. Harvey Cushing As We Knew Him. Bull N Y Acad Med. 1954 Nov;30(11):886-915.

44. Cushing H. A bio-bibliography of Andreas Vesalius. New York: Shuman's; 1943. 229 p.

45. Towpik E, Tilney NL. Harvey Cushing and his books. Surg Gynecol Obstet. 1989 Oct;169(4):366-70.

46. Zimmerman HM. The last days of Harvey Cushing. Neurol India. 1969 Dec;17(4):151-63.

47. Fulton JF. Arnold Klebs and Harvey Cushing at the 1st International Neurological Congress at Berne in 1931. Int J Neurol. 1980;14(1):103-15.

(Надійшла до редакиії 02.10.2020 p.)

Для цитирования: Рыбаков СИ. Harvey Williams Cushing - великий хирург, исследователь, эндокринолог, писатель, художник. Ендокринологія. 2020;25(4):363-374. DOI: 10.31793/16801466.2020.25-4.363.

Сведения об авторе: Станислав Иосифович Рыбаков, д-р мед. наук, проф.; ORCID: 0000-0001-8670-5260.

Личный вклад: С.И. Рыбаков — полная подготовка статьи.

Финансирование: статья подготовлена за личные средства автора.

Декларация по этике: автор задекларировал отсутствие конфликта интересов и финансовых обязательств. 